\title{
PIBID E FORMAÇÃO PARA A EDUCAÇÃO FÍSICA ESCOLAR: NO- TAS DE UMA ETNOGRAFIA
}

\author{
Tiago Nunes Medeiros \\ Faculdade Cenecista de Osório, Osório, Rio Grande do Sul, Brasil \\ Gabriel Gules Goularte \\ Colégio Marista Champagnat, Porto Alegre, Rio Grande do Sul, Brasil \\ Leandro Oliveira Rocha \\ Universidade Federal do Rio Grande do Sul, Porto Alegre, Rio Grande do Sul, Brasil \\ Fabiano Bossle \\ Universidade Federal do Rio Grande do Sul, Porto Alegre, Rio Grande do Sul, Brasil
}

\begin{abstract}
Resumo
Este estudo objetiva compreender a formação inicial de professores de Educação Física na perspectiva do Programa Institucional de Bolsa de Iniciação à Docência (PIBID). O desenho teórico-metodológico da etnografia nos permitiu interpretar os aspectos simbólicos compartilhados pelos bolsistas participantes do programa inseridos em três escolas de uma rede de ensino do interior do Rio Grande do Sul. A partir da perspectiva teórica dos Estudos Educacionais Críticos, realizamos uma descrição densa dos significados das aulas de Educação Física e interpretamos que há produção de significados compartilhados pelos participantes do estudo que diferem daqueles que embasam algumas teorias que sustentam a pesquisa.
\end{abstract}

Palavras-chave: Educação. Etnologia. Cultura. Política social.

\section{Introdução}

O Programa Institucional de Bolsa de Iniciação à Docência (PIBID) ${ }^{1}$ é um programa na escola. Ao dizer isto, estamos assumindo a convicção de nosso entendimento sobre seu potencial reflexivo e formativo nas experiências e aprendizagens produzidas desde o "chão da escola", em seu cotidiano dinâmico e complexo. Nesse sentido, o PIBID é um programa que possibilita a aproximação do estudante dos cursos de licenciatura do cotidiano das comunidades escolares, alunos, professores, equipes diretivas, supervisão pedagógica, conselho escolar, pais e funcionários, enfim, dos diferentes segmentos e agentes escolares e das práticas sociais e dos significados compartilhados no universo particular das culturas escolares. Compreender

\footnotetext{
${ }^{1} \mathrm{O}$ presente trabalho foi realizado com o apoio do Programa Institucional de Bolsa de Iniciação à Docência (PIBID), da Coordenação de Aperfeiçoamento de Pessoal de Nível Superior (CAPES) - Brasil. 
o PIBID representa para nós a possibilidade de interpretação do processo de aproximação progressiva do bolsista do universo particular que é produtor de significados sobre a docência.

Cabe destacar que, diante do contexto de crises econômicas nacionais, a continuidade do programa foi mantida através de uma redução orçamentária de $45 \%$ do repasse financeiro previsto. O que significa 274 milhões de reais nos cofres públicos e a garantia da estabilidade do programa até dezembro de 2016. Tal fato confirma que os interesses políticos e econômicos interferem diretamente na continuidade do PIBID e indica que a formação docente sofrerá implicações porque estudantes de graduação em todo país, que estão em pleno desenvolvimento qualitativo das suas funções acadêmicas no ensino superior em prol da docência para a Educação Básica, não tiveram suas bolsas renovadas.

Identificamos essa situação para, primeiro, destacar que a estratégia política de governo promove o ajuste econômico em detrimento da qualidade do ensino e, segundo, para localizar nosso posicionamento contrário às ações desta natureza. Em outras palavras, não compactuamos com a prerrogativa econômica como fim para solucionar os problemas da Educação, na qual o viés econômico sustentado na lógica neoliberal - que defende a instalação de um Estado mínimo e amplas possibilidades para o mercado especulativo econômico globalizado - obtenha a centralidade das ações governamentais diante das demandas de formação na "Pátria Educadora". Ao compreendermos e nos movimentarmos na produção de uma crítica ao mencionado, entendemos que potencializar e socializar discussões sobre projetos de Estado, programas de governo e formação docente localiza nossa posição política no cenário da Educação brasileira.

Assim, nos propusemos a investigar a formação de professores do curso de Educação Física participantes do Programa Institucional de Bolsa de Iniciação à Docência, da CAPES Brasil, contemplados com bolsas que integram o subprojeto PIBID/CAPES do curso de Educação Física de uma instituição de ensino superior (IES) privada do interior do Rio Grande do Sul. O estudo contou com seis alunos bolsistas participantes desta pesquisa, que atuaram durante um ano letivo em três escolas públicas municipais. $\mathrm{O}$ objetivo do estudo foi compreender a formação de professores de Educação Física na perspectiva dos bolsistas do Programa Institucional de Bolsa de Iniciação à Docência (PIBID).

Inicialmente, destacamos que foi realizada uma revisão de literatura nos anais do Congresso Brasileiro de Ciências do Esporte entre os anos de 2011 e 2013, nos periódicos da área da Educação Física com Qualis/CAPES de A1 a C e no banco de teses e dissertações da CAPES, uma vez que, para nós, estas bases de dados localizam a produção acadêmico-científica da Educação Física brasileira e representam um potente instrumento de consulta do conhecimento produzido na área da Educação Física. Por meio dessa revisão, a partir da combinação dos descritores PIBID e Educação Física (EFI), identificamos apenas quatro artigos publicados (confessamos que esperávamos um número maior) na Revista Didática Sistêmica, da Universidade Federal do Rio Grande (FURG), entre os anos de 2012 e 2013, em edições especiais da revista.

Tal aspecto, somado ao fato de que não encontramos publicação sobre o tema PIBID, no período em que ocorrem as revisões propostas neste estudo, na revista Pensar a Prática, de grande relevância para a área da EFI, sugere que provavelmente o tema não tenha despertado suficientemente a curiosidade dos pesquisadores da área de conhecimento e que se torna relevante sua problematização para qualificar o debate acadêmico e reflexivo sobre a aprendizagem dos pibidianos ${ }^{2}$ na tríade constituída no Ensino Superior, Educação Básica e PIBID. Não podemos deixar de destacar que atualmente, ao realizar a busca pelo descritor "PIBID" no conteúdo da revista, encontramos cinco artigos entre os anos de 2014 e 2015, mas que não

\footnotetext{
${ }^{2}$ Termo utilizado, usualmente, entre os bolsistas do PIBID em todo o Brasil e que confere alguma aproximação com o pertencimento ao grupo de bolsistas.
} 
apresentam na sua centralidade o tema PIBID e Educação Física. Deste modo, compreendemos a importância de compartilhar e socializar o produto de uma pesquisa realizada na perspectiva teórico-metodológica da etnografia. Assim sendo, apresentamos a seguir as decisões teórico-metodológicas e as discussões que permitem-nos identificar conexões entre o processo de formação em nível superior dos pibidianos de EFI da IES e como se constitui a prática nas ações que envolvem o programa PIBID na Educação Básica.

\section{Decisões teórico-metodológicas}

Para desenvolver a pesquisa, bem como potencializar o diálogo crítico e problematizador sobre a formação docente e a cultura escolar, realizamos uma etnografia. Nossa compreensão de etnografia é de que ela é uma descrição densa (GEERTZ, 1989), que se traduz em uma interpretação em profundidade dos aspectos simbólicos compartilhados na cultura das escolas e nas representações de docência circunscritas a esses contextos, entendidos como universos particulares. Os participantes da etnografia foram selecionados de acordo com o critério geográfico de proximidade com a sede, que é uma cidade da região do litoral norte do Rio Grande do Sul. Foram selecionados todos os bolsistas do subprojeto PIBID do curso de Educação Física da IES que estivessem atuando nas escolas da rede municipal deste município.

Nestas condições, o trabalho de campo teve duração de um ano letivo de imersão na realidade vivida cotidianamente por cada bolsista das três escolas participantes do estudo. A observação participante, os registros em diários de campo, os diálogos, as entrevistas e os questionários foram os instrumentos de coleta da etnografia, cujas informações foram cotejadas com a análise de documentos - do PIBID, das escolas e dos próprios pibidianos - e interpretadas à luz dos objetivos de pesquisa e da teoria dos Estudos Educacionais Críticos (APPLE, 1996). Destacamos que a validação interna das informações coletadas foi estabelecida com a triangulação das informações coletadas no campo e a leitura por parte dos participantes e a validação externa, com a colaboração de um profissional de Educação Física com mais de 30 anos de atuação com formação inicial em Educação Física e em Educação Física escolar. Fundamentalmente a partir destes movimentos, identificamos que emergiram duas categorias de análise das informações coletadas: i) Percursos e Representações de Escolas e EFI e ii) PIBID: Concepções e Práticas de Educação Física.

Respeitando as normas do Ministério da Saúde no que se refere à Resolução no 466, de dezembro de 2012 (BRASIL, 2013b), inicialmente, foi dirigida à Secretaria da Educação do Município e às escolas participantes uma carta de apresentação, solicitando permissão para a coleta de dados. Com intuito de obter a permissão dos participantes da pesquisa, foi encaminhado o Termo de Consentimento Livre e Esclarecido (TCLE), no qual, por sua vez, constaram o tema e o objetivo geral da pesquisa e as explicações sobre a participação dos envolvidos na pesquisa. Foi explicado ainda que se poderia optar por não participar (se assim se desejasse) e, no caso daqueles que concordassem em participar, que suas identidades não seriam reveladas e as informações prestadas poderiam ser utilizadas somente para fins científicos. Os documentos foram devidamente assinados e se encontram arquivados com o pesquisador principal do estudo. Na etapa final da pesquisa, todos os envolvidos tiveram acesso ao documento final e, posteriormente, foi encaminhada uma cópia para as instituições participantes do estudo.

\section{Discussão e interpretações}

Na primeira categoria de análise, "Percursos e Representações de Escolas e EFI", identificamos sentimentos de recordações ambivalentes sobre o período em que os bolsistas 
eram estudantes na Educação Básica, durante as aulas de EFI. Aspecto que permite-nos dizer que o percurso pessoal, o capital cultural, as representações de escola e escolarização, a reprodução das práticas esportivas, os PEFI e as aulas de EFI produziram "marcas" significativas na identidade particular de professor, espécies de imprinting culturais que sustentam concepções e, até mesmo, idiossincrasias (CONCEIÇÃO, 2014).

Na segunda, "PIBID: Concepções e Práticas de Educação Física", emergem as interpretações produzidas pelos bolsistas diante do que encontraram nas escolas, bem como o que aprenderam com e na escola, a partir da formação inicial e de bolsistas do PIBID.

De modo geral, o trabalho de campo da etnografia evidenciou que as atividades desenvolvidas pelos bolsistas nas escolas convergem com o entendimento que denominamos por exercício da "prática pela prática", um movimento no qual as atividades denotam um fim nelas mesmas, sem que, necessariamente, seja produzida uma reflexão sobre a intencionalidade pedagógica. Tal movimento contraria o exposto no Relatório de Gestão da CAPES 2009-2013 (BRASIL, 2013a), segundo o qual os princípios pedagógicos do PIBID, sustentados em Schön (1992) e Nóvoa (2009), são embasados na teoria da ação-reflexão-ação, cujo propósito são as aprendizagens que possibilitem compreender que a teoria não é distinta da prática e vice-versa, mas que ambas se complementam para dar sentido ao que se aprende.

Neste sentido, nos parece que o fragmento a seguir reforça este contexto de utilização da Educação Física no ambiente escolar como "disciplina prática" que, de maneira utilitária, preenche os espaços em eventos e datas comemorativas da escola, como momento de lazer, "fruição", esportivização e diversão. Assim, a bolsista é convidada a realizar atividades recreativas com as turmas de $1^{\circ}$ ano dos turnos da manhã e da noite em razão da Semana da Criança, evento desenvolvido na escola em comemoração ao Dia da Criança, como segue o registro do diário de campo:

Cada coluna é separada por coletes amarelos e vermelhos, para realização de estafeta competitiva. As crianças apresentaram dificuldade de compreensão da tarefa. A partir do momento em que as bolsistas do PIBID começaram a intervir de modo mais enfático, conduzindo as crianças pela mão, os alunos realizaram a atividade de modo mecânico. Nesse momento, Sandra ${ }^{3}$ passa a incentivar as crianças com elogios individualizados, reforçando a competitividade. Finalizada a aula, as crianças correm em direção ao prof. unidocente e o cercam com abraços e beijos. Ele e a bolsista do PIBID conduzem as crianças para a sala de aula (ESCOLA CAIEIRAS, DIÁRIO DE CAMPO, OBSERVAÇÃO N 14, 9/10/2014).

Desse modo, Sandra teria apenas mais uma turma depois do recreio. Questionamos, então, sobre as atividades realizadas e sobre qual seria a avaliação da aula. O que gostaria de desenvolver com a aula? Enfim, qual a intencionalidade pedagógica? Sandra responde que era para "divertir as crianças, movimentá-las" e considera que a aula ocorreu sem transtornos: "Foi tudo muito tranquilo", diz ela em uma autoavaliação. Nota-se um deslocamento da intenção pedagógica para outra perspectiva, de atendimento da ordem e da ocupação do tempo das crianças preenchido com "atividades".

Destacamos que os bolsistas estão expostos à realidade da escola e essa condição faz com que tenham de assumir as características e a cultura escolar a qual estão vivenciando. Segundo Julia (2001), a cultura escolar deve remeter à compreensão de elementos que a descrevem a partir de um conjunto de normas que definem conhecimentos a ensinar e que estas práticas coordenadas podem sofrer influências, conforme as finalidades da religião, sociopolíticas ou de socialização da época.

\footnotetext{
${ }^{3}$ Os nomes dos participantes da pesquisa e escolas pesquisadas são fictícios.
} 
Evidenciamos durante o trabalho de campo que a cultura escolar reconhece nas necessidades da escola a possibilidade de gerenciamento dos horários dos bolsistas, a fim de suprir a demanda do quadro de professores. Então, não raramente, os bolsistas do programa passam a ser aceitos e/ou vistos na comunidade escolar como membros efetivos da escola, ganhando status de professor.

Essa condição é reforçada pelos bolsistas, quando se colocam à disposição da escola para realizar as tarefas que lhes são solicitadas - por exemplo, assumir turmas do Ensino Fundamental, substituindo professores ausentes, seja para realizar as tarefas da Educação Física, seja para aplicar os conteúdos curriculares que estão sendo desenvolvidos naquele período letivo -, assim como para atuar como estagiários, e isso tem reforçado uma condição diferente da nossa compreensão sobre esse tema dentro dos princípios metodológicos do PIBID.

Outro momento que evidencia o distanciamento entre os princípios metodológicos do PIBID e o que encontramos na pesquisa de campo se refere às entrevistas realizadas com as supervisoras do programa na escola, que reforçam as categorias de análise, principalmente o estado de precarização das escolas, como veremos nestes dois fragmentos de informações coletadas no campo:

O programa para a escola é o apoio para a escola, embora eles não sejam substitutos, não estão substituindo, mas eles estão aqui nos apoiando [...] No currículo nós não tínhamos EFI, era o professor unidocente, hoje eles têm o bolsista trabalhando com eles e com a EFI [...] É uma troca para os dois lados, um apoia o outro, escola e programa. (ROSA INÁCIA JOAQUINA, ESCOLA MARECHAL OSÓRIO, ENTREVISTA N ${ }^{\circ} 7$, REALIZADA DIA 2/12/2014).

[...] Os bolsistas da EFI vieram satisfazer melhor as necessidades da escola em função da EFI fazer parte da itinerância [...]. Acrescentaram muito na escola, a gente vê eles como professores do corpo docente (MANUELA LUÍSA, ESCOLA 24 DE MAIO, ENTREVISTA N ${ }^{\circ} 12$, REALIZADA DIA 19/12/2014).

Neste momento entendemos que as forças que forjam culturas hegemônicas (GIROUX, 1997) estão atuando no sentido de reforçar elementos de uma cultura escolar vigente. Assim, nos propusemos a problematizar a essência do PIBID para aquilo que se destina, ou seja, a formação reflexiva para a docência. Mas o que encontramos foi a utilização dos recursos humanos do PIBID para contemplar carências e necessidades da escola precarizada pela ordem econômica, política e social neoliberal. Amparados na literatura que sustenta o estudo, ou seja, nos Estudos Educacionais Críticos (APPLE, 1996), reconhecemos a necessidade de compreensão das forças que atuam desde o contexto macrossocial e que são determinantes nas implicações da cultura escolar e da formação inicial de professores de Educação Física. Neste sentido, na perspectiva de Paulo Freire, "ensinar exige reflexão crítica sobre a prática" (FREIRE, 1996), ou seja, a prática docente crítica envolve movimento dinâmico, dialético, entre o fazer e o pensar sobre o fazer. Na formação docente, o aprendiz de educador deve assumir que pensar certo não é presente dos "deuses", dos manuais ou guias de professores; pensar certo compreende o esforço de produzir conhecimento com o professor formador (FREIRE, 1996).

Destarte, foram produzidas potentes discussões durante as reuniões do programa e no seminário do PIBID que ocorrerá na IES, promovendo reflexão e diálogo sobre o ensino da Educação Física Escolar e o papel do programa na escola, que vieram esclarecer dúvidas e fomentar novas discussões sobre o ensino da Educação Física, tanto na Educação Básica 
quanto no Ensino Superior, como podemos perceber nestes dois fragmentos retirados do trabalho de campo:

[...] Desse modo, a maioria das escolas optou por desenvolver suas atividades de EFI com os anos iniciais do Ensino Fundamental. [...] As escolas não têm condições físicas, adequadas, para receber uma quantidade extra de alunos no turno oposto (SEMINÁRIO PIBID/IES, 13/11/2014, RODA DE CONVERSA, SALA 304, ÁUDIO 2).

Lá na escola não tenho o acompanhamento da unidocente, então, quando estou realizando as atividades com as crianças e tenho algum tipo de dúvida, não sei se vou conseguir atingir os objetivos da aula (SEMINÁRIO PIBID/IES, 13/11/2014, RODA DE CONVERSA, SALA 305, ÁUDIO 3).

Partindo da premissa proposta por Tardif (2013), a vida profissional docente é construída em quatro etapas, sendo as duas primeiras de maior interesse no momento. Podemos afirmar que os bolsistas do PIBID se apresentaram imersos em um contexto de formação inicial caracterizada por ser anterior à entrada na universidade, ou seja, consiste nas experiências vivenciadas durante a formação escolar (Educação Básica) e posteriormente se transformou na formação universitária inicial.

Consideramos que as experiências da formação inicial durante a Educação Básica estão constantemente presentes no trabalho de campo. Neste sentido, encontramos compartilhada entre os bolsistas do PIBID/EFI/FACOS uma fervorosa crítica sobre essa prática. Assim, percebemos que os bolsistas passam a rejeitar o modelo vivenciado na Educação Básica e constituir como adequado e/ou ideal o modelo experimentado no Ensino Superior.

O PIBID se propõe a desenvolver uma proposta metodológica de iniciação à docência, pautada na tríade ensino, pesquisa e extensão. Seu desenvolvimento ocorre a partir das ações recorrentes do processo de formação inicial dos bolsistas para as atividades na Educação Básica, na perspectiva de potencializar a formação acadêmica para a licenciatura, assim qualificando e minimizando o impacto dos primeiros anos de atuação da carreira docente na escola. Como menciona Hubermann (2007), a entrada na carreira docente significa o confronto inicial com a realidade e suas múltiplas facetas, podendo gerar um "choque de real", tanto de aspectos positivos quanto negativos.

Estar na escola para o PIBID significa conviver com a comunidade escolar imerso em documentos como o regimento escolar e o PPP da escola; identificar a cultura da escola; realizar planejamentos; participar do conselho de classe, reuniões administrativas e pedagógicas; festas, seminários, congressos, jogos, entrega de boletim e/ou parecer, formação continuada e eventos promovidos pela escola e/ou pela rede de ensino.

No transcorrer do trabalho de campo, percebemos a necessidade constante dos bolsistas em compreender o seu papel enquanto sujeito em formação inicial, pois, após suas atividades na escola, invariavelmente, buscavam dialogar, debater e questionar sobre as suas práticas e como elas poderiam promover um sentido à formação dos alunos da Educação Básica e consequentemente a sua própria formação.

Para as autoras Farias e Rocha (2012), o sucesso do PIBID está atrelado a uma política pública que visa incentivar o interesse pelo magistério e fortalecer a formação inicial de futuros professores de Educação Básica mediante os anseios reais da escola. Deste modo, o Relatório de Gestão da CAPES 2009-2013 trata de enfatizar que a definição dos níveis a serem atendidos e a prioridade das áreas cabem às IES participantes, em consonância com a rede de ensino, para elaborar, a partir da necessidade educacional e social local ou da região, seus projetos institucionais. 
Diante das informações coletadas, questionamos se a reflexão crítica tem sido potencializada no PIBID e como este movimento é apropriado pela academia - uma vez que o estudo de revisão realizado nas bases de dados revelou certa invisibilidade do tema - e identificamos que há uma relação diferente dos participantes do estudo com o que embasa o PIBID e o referencial teórico dos estudos educacionais críticos (APPLE, 1996).

A ação-reflexão-ação prevista e idealizada na perspectiva do programa parece não se efetivar concretamente em função de concepções - algumas construídas anteriormente à formação inicial em Educação Física - dos estudantes com relação ao que a Educação Física assume na condição de componente curricular da Área das Linguagens, bem como em uma perspectiva acrítica de resolução dos problemas e carências diversas que as escolas enfrentam em seu cotidiano. $\mathrm{O}$ bolsista, dessa forma, parece não potencializar a reflexão sobre a ação educativa, aprendendo mais a partir de demandas da ordem administrativa da escola e menos da pedagógica - e crítica.

\section{Considerações finais}

No esforço de descrever densamente o que é compartilhado nas culturas escolares pesquisadas, destacamos a potencialidade das reflexões e discussões estabelecidas durante as reuniões do PIBID/EFI, na busca para compreender a docência na contemporaneidade, a precarização e as práticas das escolas e o significado da Educação Física. Isso porque, diante das demandas e urgências de ordem prática, ou seja, de suprir a necessidade da escola de preenchimento do espaço vazio destinado ao PEFI pelo bolsista do PIBID ou pelo estagiário de EFI, o bolsista do PIBID não conseguia problematizar a docência nem compreender com clareza sua mediação na escola e as relações que demandavam representações de docência na EFI. Nesse sentido, entendemos que a ação-reflexão-ação, descrita por Schön (1992), ficou, muitas vezes, do lado de fora da escola e à mercê de oportunidades fomentadas em outros espaços - nesse caso, as reuniões na IES.

Desse modo, o bolsista passa a identificar as condições e práticas impostas pela escola e agir de modo proativo para suprir essas necessidades, de maneira redentora (FISCHMAN; SALES, 2010). A comunidade escolar passa, então, a identificar o bolsista como "um dos seus", ou seja, alguém que - superficialmente em função da conjuntura e da particularidade da cultura escolar, reveladora de carências e desassistências - assume a condição de "professor", porque colabora, "abraça junto". Mesmo que não seja seu propósito, suas ações voluntariamente comprometidas com a escola naturalmente os colocam nesta condição, até porque o fato de ser aceito na escola para a realização das atividades de iniciação à docência é permeado pelos interesses e pelas necessidades do contexto escolar e produz, de maneira significativa, a compreensão desde a iniciação à docência de um fazer na urgência e de acordo com o quadro de desassistência para com a Educação. A compreensão sobre a docência nas escolas pode ser reveladora dos significados de docência na contemporaneidade, demandando reflexão constante sobre as armadilhas produzidas nos contextos particulares sobre outras representações que estão em disputa por legitimidade e, por vezes, parecem mais adequadas à resolução de problemas à moda de uma racionalidade "ingênua" (FREIRE, 1996).

Esse movimento leva à interpretação sobre elementos significativos na compreensão das aprendizagens dos bolsistas inseridos nesta perspectiva prática das aulas de EFI. Os bolsistas do programa, no esforço de compreender o papel da EFI na escola, passam a buscar referências na sua formação inicial em dois momentos distintos. O primeiro tratou das experiências constituídas na Educação Básica. Neste ponto, gostaríamos de ressaltar o empenho dos bolsistas na tentativa de não reproduzir tais experiências. $\mathrm{O}$ segundo momento aborda a reprodução das práticas pedagógicas esportivizantes vivenciadas na graduação como modelo para as aulas de EFI para alunos dos anos iniciais do Ensino Fundamental. 
Outro elemento que emerge, de modo significativo, é a reprodução de práticas pedagógicas esportivizantes e de baixa produção de uma crítica consistente ao sistema. Contudo, isso não deve ser entendido como um movimento "apocalíptico" de abandono da transformação e emancipação dos sujeitos, pelo contrário, entendemos que possa potencializar a problematização dos fenômenos e das forças que incidem sobre os bolsistas na conjuntura do processo de formação de professores e do processo de escolarização.

Nessa perspectiva, emerge do trabalho de campo a necessidade de potencializar diálogos e reflexões sobre tais condições enfrentadas na escola durante as próprias reuniões do PIBID/EFI na IES. Ou seja, a necessidade de ação-reflexão-ação para uma condição crítica sobre o que os bolsistas estavam fazendo na escola surge de modo consistente e potencializado pelo seminário do PIBID realizado na IES no ano de 2014, no qual estiveram reunidos os bolsistas de todo o programa, no sentido de promover um diálogo sobre a escola e suas relações com a escola. Nesse sentido, permitir, especificamente, que os bolsistas do PIBID/EFI pudessem falar, mas principalmente escutar os demais colegas foi um momento de aprendizagem crítica e reflexiva sobre a ação que provocou inquietação e movimento no programa.

Destacamos que esse foi um momento crítico, pois os bolsistas do PIBID/EFI passaram a questionar o seu papel na escola, o que a escola ensina e o que eles aprendem com a escola, o que é a docência. Desse modo, os participantes da pesquisa passaram a questionar e dar sentido à sua presença na escola ao se posicionarem sobre atitudes ou ações que competem ao estagiário e não ao bolsista do PIBID.

O trabalho de campo evidenciou que o PIBID é um programa na escola. Afirmar que o PIBID é um programa na escola não é uma interpretação original de nossa parte, visto que outros já o fizeram, mas reforça a perspectiva de aprendizagem sobre a docência no contexto dinâmico das escolas. Para Wittizorecki (2009), a docência é mais do que o momento da aula, trata das relações que se concretizam em um ambiente permeado por tensões, conflitos e dilemas da sociedade contemporânea.

Nesse sentido, a aprendizagem sobre a docência no PIBID poderia contemplar mais do que o momento de aula, sobretudo promover uma aproximação dos estudantes ao campo, ao "chão da escola" e aos seus significados plurais. Não se trataria de uma confusa relação de proximidade com os estágios, mas de uma apropriação gradual do ethos da escola, a compreensão sobre o que ocorre naquele lugar, por que ocorre, quais seriam as forças que atuam para as representações construídas sobre a escola e a docência e, evidentemente, sobre a Educação Física na condição de componente curricular. Identificamos que o programa proporcionou aprendizados aos bolsistas do PIBID/EFI, oferecendo-lhes experiências reais sobre a prática docente no "chão das escolas", em consonância com os objetivos do programa para a sua formação inicial como licenciando de EFI.

Nesse sentido, Bourdieu (2001) e Bourdieu e Passeron (2014) tratam do conceito de habitus a partir da necessidade de compreensão das relações de afinidade entre o comportamento dos agentes e as estruturas e condicionantes sociais, em que um sistema de arranjos duráveis e transponíveis que, integrando todas as experiências passadas, funcionam a cada momento como uma matriz de percepções, de críticas e de ações, tornando possível a realização de tarefas infinitamente diferenciadas, graças às mudanças analógicas de esquemas.

Para Setton (2002, p. 63), o conceito de habitus de Bourdieu (2001) surge como "[...] um conceito capaz de conciliar a oposição aparente entre realidade exterior e as realidades individuais". Desse modo, tal conceito respeita um sistema de esquemas individuais, estruturados socialmente a partir das experiências práticas orientadas para funções e ações do agir cotidiano. Ou seja, as ações, comportamentos, escolhas individuais não derivam dos planejamentos, são antes produtos da relação entre um habitus e as pressões e estímulos de um determinado momento. 
Tendo como base o conceito de habitus proposto por Bourdieu (2001), consideramos que os bolsistas do programa, ao serem expostos a um sistema de disposições rígido e condicionante como a escola, buscaram nas suas experiências anteriores meios imediatos de fornecer sentido às suas práticas. Tal conceito também forneceu subsídio para compreender que o habitus não representa a reprodução e a conservação de uma lógica social, mas sim se constitui através de estratégias e práticas individuais dispostas a reagir ao meio, adaptar-se e contribuir com novos elementos de reflexão sobre a prática.

Consideramos que a precarização docente e escolar, associada à recente entrada na formação inicial no Ensino Superior, produziram um imediatismo das ações práticas dos bolsistas quando foram submetidos à condição de frequentar o ambiente escolar, de tal modo que não foram capazes de potencializar a reflexão crítica sobre os aprendizados produzidos na academia e tampouco nas reuniões do PIBID. Mesmo que o trabalho de campo tenha mostrado que as discussões nas reuniões do programa avançaram no sentido da reflexão para a ação, o próprio campo demonstrou que a crítica e a reflexão são deixadas do lado de fora do portão das escolas participantes do PIBID.

Entendemos que o presente estudo traz uma contribuição crítica e reflexiva sobre as aprendizagens atribuídas aos bolsistas do programa em três aspectos específicos: a escola, a IES e o PIBID, que constituem um tripé de análise e são investigados a partir de uma etnografia, a qual se encarrega de atribuir significado aos símbolos que se apresentam durante o trabalho de campo. Símbolos evidenciados em duas categorias de análise propostas: "Percursos e Representações de Escolas e EFI" e "PIBID: Concepções e Práticas de Educação Física", que permitiram uma potente discussão sobre o campo.

\title{
PIBID AND FORMATION TO THE PHYSICAL EDUCATION SCHOOL: NOTES OF AN ETHNOGRAPHY
}

\begin{abstract}
This study aims to understand the initial training of teachers of physical education from the perspective of Institutional Scholarship Program initiation into Teaching. The theoreticalmethodological design of Ethnography has allowed us to interpret the symbolic aspects shared by scholars program participants entered into three schools of Education in the interior of Rio Grande do Sul. From the theoretical perspective of Critical Educational Studies we performed a dense description of the meanings of the physical education classes and interpret that there is production of shared meanings by the participants of the study that differ from those that supports some theories supporting the searches.
\end{abstract}

Keywords: Education. Ethnology. Culture. Public policy.

\section{PIBID Y FORMACIÓN PARA LA EDUCACIÓN FÍSICA DE LA ESCUELA: NOTAS DE UNA ETNOGRAFIA}

\section{Resumen}

Este estudio intenta comprender la formación inicial de profesores de Educación Física desde la perspectiva de la iniciación del Programa Institucional de Bolsas de Iniciação à Docencia. El diseño teórico metodológico de la etnografía nos permitió interpretar los aspectos simbólicos compartidos por los becarios participantes del programa que actúan en tres escuelas de de la enseñanza básica de ciudades del interior de Rio Grande do Sul. Desde la perspectiva teórica de los estudios educativos críticos realizamos una descripción densa de los significados de las clases de educación física e interpretamos que existe producción de significados comparti- 
dos por los participantes del estudio que difieren de lo que es compatible con algunas teorías que sustentan las búsquedas.

Palabras clave: Educación. Etnología. Cultura. Política social.

\section{Agradecimentos}

Primeiro autor é bolsista do Programa Institucional de Bolsa de Iniciação à Docência, Coordenador de Área de subprojeto Educação Física da Faculdade Cenecista de Osório.

Apoio: CAPES

\section{Referências}

APPLE, M. W. Cultural politics and education. New York (USA): Columbia University/Teachers College Press, 1996.

BOURDIEU, P. Meditação pascalianas. Tradução Sérgio Miceli. Rio de Janeiro: Bertrand Brasil, 2001.

BOURDIEU, P.; PASSERON, J. C. A reprodução: elementos para uma teoria do sistema de ensino. Tradução Reynaldo Bairão. 7 ed. Petrópolis: Vozes, 2014.

BRASIL. Fundação CAPES. Ministério da Educação. Diretoria de Formação de Professores da Educação Básica. Relatório de Gestão 2009-2013. Brasília: CAPES, 2013a. p. 67-116. Disponível em: <http://www.capes.gov.br/images/stories/download/bolsas/2562014relatrorio-DEB-2013-web.pdf >. Acesso em: 20 maio 2014.

BRASIL. Ministério da Saúde. Conselho Nacional de Saúde. Diário Oficial da União. Resolução n. ${ }^{\circ}$ 466, de 13 de junho de 2013, n. 12, seção 1, p. 59, 2013b. Disponível em: <http://conselho.saude.gov.br/resolucoes/2012/Reso466.pdf $>$. Acesso em: 8 jul.2014.

CONCEIÇÃO, V. J. S. da. A construção da identidade docente de professores de Educação Física no início da carreira: um estudo de caso etnográfico na rede municipal de ensino de Porto Alegre - RS. 2014. 305 f. Tese (Doutorado) - Programa de Pós-graduação em Ciências do Movimento Humano, Universidade Federal do Rio Grande do Sul, Porto Alegre, 2014.

FARIAS, I. M. S. de; ROCHA, C. C. T. PIBID: uma política de formação docente inovadora? Revista Cocar, Belém, v. 6, n. 11, p. 41-49, jan./jul. 2012.

FISCHMAN, G. E.; SALES, S. R. Formação de professores e pedagogias críticas: é possível ir além das narrativas redentoras? Revista Brasileira de Educação, Rio de Janeiro, v. 15, n. 43, p. 7-20, jan./abr. 2010.

FREIRE, P. Pedagogia da autonomia: saberes necessários à prática educativa. São Paulo: Paz e Terra, 1996.

GEERTZ, C. A interpretação das culturas. Rio de Janeiro: LTC, 1989. 
GIROUX, H. A. Professores como intelectuais transformadores. In: GIROUX, H. A. (Org.). Os professores como intelectuais transformadores: rumo a uma pedagogia crítica da aprendizagem. Porto Alegre: Artes Médicas, 1997. p. 157-164.

HUBERMAN, M. O ciclo de vida profissional dos professores. In: NÓVOA, A. (Org.). Vidas de professores. 2. ed. Porto: Porto, 2007. p. 31-61.

JULIA, D. A. Cultura escolar como objeto histórico. Revista Brasileira de História da Educação, n. 1, p. 9-43, jan./jun. 2001.

NÓVOA, A. Para uma formação de professores construída dentro da profissão. Revista Educacion, Madri, n. 350, p. 203-218, set./dez. 2009.

SCHÖN, D. A. Formar professores como profissionais reflexivos. In: NÓVOA, A. Os professores e sua formação. Lisboa: Dom Quixote, 1992.

SETTON, M. da G. J. A Teoria do habitus em Pierre Bourdieu: uma leitura contemporânea. Revista Brasileira de Educação, Rio de Janeiro, n. 20, p. 60-70, maio/jun./jul./ago. 2002.

TARDIF, M. Saberes docentes e formação profissional. 15 ed.. Petrópolis: Vozes, 2013.

WITTIZORECKI, E. S. Das muitas coisas que faz o professor de educação física na escola. In: MOLINA NETO, V.; BOSSLE, F.; SILVA, L. O. E; SANCHOTENE, M. U. (Org.). Quem aprende? Pesquisa e formação em educação física escolar. Ijuí: Inijuí, 2009. p. 93-103.

Recebido em: 23/03/2016

Revisado em: 09/09/2016

Aprovado em: 29/08/2017

Endereço para correspondência:

proftmedeiros@gmail.com

Tiago Nunes Medeiros

Faculdade Cenecista de Osório

Rua 24 de Maio, 141,

Centro - Osório/RS 